\title{
A new computational approach to analyze human protein complexes and predict novel protein interactions Sara Zanivan ${ }^{* \dagger}$, Ilaria Cascone ${ }^{* \neq}$, Chiara Peyron§, Ivan Molineris\$, Serena Marchio*, Michele Caselle ${ }^{\circledR}$ and Federico Bussolino ${ }^{\text {«* }}$
}

\begin{abstract}
Addresses: *Department of Oncological Sciences and Division of Molecular Angiogenesis, Institute for Cancer Research and Treatment (IRCC), University of Torino Medical School, Strada Provinciale, I-1006o Candiolo (Turin), Italy. ${ }^{\dagger}$ Max-Planck Institute for Biochemistry, Department of Proteomics and Signal Transduction, Am. Klopferspitz, D-82152 Martinsried, Germany. ${ }^{\ddagger}$ Inserm U528, Institut Curie, 75248 Paris, France. §Department of Theoretical Physics, University of Torino and INFN, Via P Giuria 1, I-10125 Turin, Italy.
\end{abstract}

$\ltimes$ These authors contributed equally to this work.

Correspondence: Sara Zanivan. Email: zanivan@biochem.mpg.de

Published: 4 December 2007

Genome Biology 2007, 8:R256 (doi:10.1 186/gb-2007-8-12-r256)

The electronic version of this article is the complete one and can be found online at http://genomebiology.com/2007/8/I2/R256
Received: 24 August 2007

Revised: 14 November 2007

Accepted: 4 December 2007

(c) 2007 Zanivan et al.; licensee BioMed Central Ltd.

This is an open access article distributed under the terms of the Creative Commons Attribution License (http://creativecommons.org/licenses/by/2.0), which permits unrestricted use, distribution, and reproduction in any medium, provided the original work is properly cited.

\begin{abstract}
We propose a new approach to identify interacting proteins based on gene expression data. By using hypergeometric distribution and extensive Monte-Carlo simulations, we demonstrate that looking at synchronous expression peaks in a single time interval is a high sensitivity approach to detect co-regulation among interacting proteins. Combining gene expression and Gene Ontology similarity analyses enabled the extraction of novel interactions from microarray datasets. Applying this approach to $\mathrm{P} 2 \mathrm{I}$-activated kinase $\mathrm{I}$, we validated $\alpha$-tubulin and early endosome antigen $\mathrm{I}$ as its novel interactors.
\end{abstract}

\section{Background}

The cell is a complex system involving a heterogeneous and highly dynamic set of proteins whose ability to interact and form complexes is critical for cellular activity and regulation [1]. A major goal, therefore, is the complete identification of the interactome. Different high-throughput experimental approaches have been developed to characterize the interactomes of several organisms. Yeast two hybrid screens allow binary interactions to be defined while tandem affinity purification (TAP)-tag followed by mass spectrometry analysis is used to purify and identify components of multi-protein complexes [2-5]. Up to now, data have been mostly generated by studying simple organisms such as Saccharomyces cerevisiae, Caenorhabditis elegans and Drosophila melanogaster $[6,7]$. For human cells, published experimental results are collected in databases like MINT (Molecular Interactions database) and HPRD (Human Protein Reference Database) $[8,9]$, but the amount of information is still largely limited. Moreover, data have been obtained from different cellular models and using different techniques, thus rendering it difficult to build a global network of interactions or to extrapolate information about the composition of multi-protein complexes.

Computational approaches may help to address these crucial issues [10-17]. The current idea is that proteins forming a supra-molecular complex are transcribed simultaneously and standard Pearson's analysis has been extensively applied to gene expression datasets to support this concept $[12,14,15,17,18]$. In general, good results are obtained with 
this method if protein interactions of stable protein complexes are studied, but it is less efficient in other cases $[12,14]$. A paradigmatic example is the application of Pearson's analysis to gene expression datasets of the yeast cell-cycle. A strong and significant correlation can be obtained for permanent protein complexes, but only weak correlations are seen for the transient ones [14]. A similar conclusion resulted from the analysis of some human gene profiles [12].

In this paper we present a new approach for the detection of putative protein interactions based on expression data. Besides the identification of permanent complexes, it is also capable (at least for well synchronized samples) of reliably identifying interactions among proteins belonging to transient complexes. This approach is based on two observations. Firstly, protein-protein interactions are more easily identified if the interacting protein pair belongs to a multi-protein complex. This is a direct consequence of the fact that the features used to identify the interactions (that is, correlations in expression data) display a much higher signal to noise ratio if multiple correlations are looked for simultaneously. Therefore, we focused on tracking interactions within protein complexes, even though our algorithm can, in principle, identify any type of protein-protein interaction. The second observation is that while Pearson's correlators are very effective at identifying permanent complexes, which remain assembled throughout most experimental time-points, they are less suitable for transient complexes, which are assembled for only one or a few time-points. To overcome this problem, we propose a new method to extract putative human interacting proteins from microarray gene expression data by looking at the presence of synchronous expression peaks in time course experiments of synchronized HeLa cells [19]. This is further supported by the recent observation in yeast that the timing of transcription during the cell-cycle is indicative of the timing of protein complex assembly [20].

This approach allowed us to address interactions characterized by low, but not negligible, statistical significance, which would instead be completely filtered out in the Pearson-based analysis. To further enhance the signal to noise ratio we combined this analytical procedure with a standard Gene Ontology (GO) [21] search. This filter turns out to be very effective, since it is based on input information completely independent from data exploited in the previous analysis step.

To test the performance of our approach and compare it with the standard Pearson-based one, we established and tested a set of 32 permanent and transient complexes. The application of our method shows its effectiveness in detecting protein interactions in permanent and transient complexes. We also observed that, as expected, the proposed technique performs better as the synchronization of the dataset improves. To specifically test the applicability of our method in a precise biological context, we used it to explore novel putative interacting partners for serine/threonine p21-activated kinase (PAK)1. PAK1 is a kinase downstream of the Rho family of small GTPases, which participates in the formation of several dynamic and transient transductosomes [22]. We also provide experimental evidence confirming the interactions predicted by our algorithm between PAK1 and $\alpha$-tubulin as well as PAK1 and early endosome antigen (EEA)1, a coiled coil dimer that is crucial for endosome fusion in vitro [23].

\section{Results \\ Starting data: known protein complexes and microarray datasets}

Up to now there are no databases for genome-wide multi-protein interactions in mammals. Thus, we focused our study on 11 permanent and 21 transient human complexes of different sizes that are well characterized in the literature (Table 1, and see Materials and methods). Since transient complexes display dynamic properties, we analyzed microarray data from several temporal series describing a dynamic cellular condition. For this, we selected from the Stanford Microarray Database [24] three independent datasets analyzing the cell-cycle of HeLa cells synchronized either with double thymidine (Thy-Thy) or thymidine-nocodazole (Thy-Noc). In particular, only data from the first full cell-cycle (14 hours long) after synchronization were considered.

\section{Gene expression analysis of human protein complexes by Pearson correlation coefficient}

To extract putative protein-protein interactions from gene expression data, we first evaluated the Pearson's correlation for each pair of genes in the above described HeLa datasets. To assess if the number of highly correlated components had been obtained by chance, results were compared with the global behavior of the dataset by a standard hypergeometric test (Materials and methods).

Among the 32 analyzed protein complexes, 23 showed a $p$ value lower than 0.05, including 5 in Thy-Thy dataset 2 (ThyThy2; Additional data file 1a), 10 in Thy-Thy dataset 3 (ThyThy3; Additional data file $1 \mathrm{~b}$ ) and 8 in the Thy-Noc dataset (Table 2). Among them (in particular in the very low $p$ value range), a dominance of permanent with respect to transient protein complexes was observed. As an example, proteasome and small ribosomal subunit (SRS), which are well known stable complexes, were both characterized by very low $p$ values in at least two datasets. However, we also found several complexes in which the number of highly correlated genes was clearly not statistically significant (that is, with a $p$ value $\geq 0.7$ ). In particular, this occurred in 15,11 and 12 complexes in the Thy-Thy2, Thy-Thy3, and Thy-Noc datasets, respectively, including both permanent and transient complexes. RNA polymerase III is an example of a permanent complex without a significant $p$ value in all three datasets. 
Table I

Set of known human multi-protein complexes analyzed

\begin{tabular}{|c|c|c|c|c|}
\hline \multirow[b]{2}{*}{ Protein complex } & \multirow[b]{2}{*}{ Complex type } & \multicolumn{3}{|c|}{ Number of genes } \\
\hline & & Thy-Thy2 & Thy-Thy3 & Thy-Noc \\
\hline ATP_FO & Permanent & 7 & 10 & 10 \\
\hline ATP_FI & Permanent & 4 & 3 & 3 \\
\hline $\operatorname{cox}$ & Permanent & 7 & 6 & 8 \\
\hline SRS & Permanent & 16 & 20 & 20 \\
\hline LRS & Permanent & 15 & 18 & 18 \\
\hline MLRS & Permanent & 22 & 36 & 37 \\
\hline MSRS & Permanent & 20 & 30 & 30 \\
\hline Proteasome & Permanent & 21 & 21 & 23 \\
\hline PD & Permanent & 6 & 7 & 7 \\
\hline RNA Pol II & Permanent & 10 & 10 & 10 \\
\hline RNA Pol III & Permanent & 4 & 6 & 5 \\
\hline AP2 & Transient & 2 & 4 & 4 \\
\hline APC & Transient & 5 & 8 & 8 \\
\hline Arp2-3 & Transient & 6 & 3 & 5 \\
\hline ARC & Transient & 4 & 5 & 5 \\
\hline Centrosome & Transient & 42 & 50 & 51 \\
\hline Dynactin & Transient & 7 & 9 & 7 \\
\hline Exocyst & Transient & 7 & 7 & 7 \\
\hline Exosome & Transient & 3 & 5 & 5 \\
\hline FA & Transient & 37 & 46 & 47 \\
\hline GTC & Transient & 5 & 6 & 6 \\
\hline Nucleopore & Transient & 27 & 29 & 30 \\
\hline Nucleosome & Transient & 17 & 24 & 24 \\
\hline ORC & Transient & 4 & 5 & 6 \\
\hline RFC & Transient & 3 & 4 & 4 \\
\hline SRP & Transient & 3 & 5 & 4 \\
\hline SCF & Transient & 3 & 3 & 3 \\
\hline SNARE complex & Transient & 7 & 7 & 7 \\
\hline SWI-SNF & Transient & 12 & 10 & 12 \\
\hline TAFIID & Transient & 8 & 13 & 13 \\
\hline TRAPP & Transient & 2 & 5 & 6 \\
\hline VHL & Transient & 4 & 4 & 4 \\
\hline
\end{tabular}

The number of genes representing each protein complex is reported for the three analyzed HeLa cell-cycle datasets. AP2, adaptor-related protein complex 2; APC, anaphase promoting complex; ARC, axin related complex; ATP_FO, ATP synthase, $\mathrm{H}+$ transporting, mitochondrial F0 complex; ATP_FI, ATP synthase, $\mathrm{H}+$ transporting, mitochondrial FI complex; COX, cytochrome coxidase; FA, focal adhesion; GTC, golgi transport complex; MSRS, mitochondrial small ribosomal subunit; ORC, origin recognition complex; PD, pyruvate dehydrogenase; RNA Pol II, RNA polymerase II; SRP, signal recognition particle; TRAPP, trafficking protein particle complex; VHL, von Hippel-Lindau complex.

Gene expression analysis of human protein complexes by expression peaks method

As previously observed, the Pearson-based method was unable to detect significant correlations (that is, with a $p$ value not $\geq 0.7$ ) for almost half of the tested complexes. To improve the level of detection, we set up an alternative approach, which we call the 'expression peaks method'. Gene expression was analyzed every one (for Thy-Thy datasets) or two (for the ThyNoc dataset) hours by computing the variation of mRNA levels between consecutive time points. A threshold was then defined on computed differences, which represents the value above which we considered the increase of expression between two consecutive time points a peak of expression. Next, we placed all computed expression values in a binary 1o system where 1 represents an expression peak. By calculating the expression peaks for each gene along the cell-cycle in each dataset, we found that a high percentage of genes participating in the same complex peaked synchronously at least in one temporal interval (Table 3 for the Thy-Noc dataset, and Additional data file 3 for the Thy-Thy datasets). Since there was more than one peak of expression per gene, we established the peak of expression of each complex as the time 
Table 2

$P$ values for Thy-Noc dataset

\begin{tabular}{|c|c|c|c|c|c|c|c|c|}
\hline \multirow[b]{2}{*}{$\begin{array}{l}\text { Protein } \\
\text { complex }\end{array}$} & \multicolumn{7}{|c|}{ Peaks of expression ( $p$ value) } & \multirow{2}{*}{$\begin{array}{c}\text { Pearson } \\
(p \text { value })\end{array}$} \\
\hline & $2 \mathrm{~h}-0 \mathrm{~h}$ & $4 \mathrm{~h}-2 \mathrm{~h}$ & $6 \mathrm{~h}-4 \mathrm{~h}$ & $8 \mathrm{~h}-6 \mathrm{~h}$ & $10 \mathrm{~h}-8 \mathrm{~h}$ & $12 \mathrm{~h}-10 \mathrm{~h}$ & $14 \mathrm{~h}-12 \mathrm{~h}$ & \\
\hline AP2 & $3.67 \mathrm{E}-0 \mathrm{I}$ & 7.47E-0I & $7.05 \mathrm{E}-0 \mathrm{I}$ & $1.00 \mathrm{E}+00$ & $4.78 \mathrm{E}-0 \mathrm{I}$ & $6.26 \mathrm{E}-0 \mathrm{I}$ & $3.73 \mathrm{E}-0 \mathrm{I}$ & $1.00 \mathrm{E}+00$ \\
\hline ARC & $3.49 \mathrm{E}-02$ & $1.00 \mathrm{E}+00$ & $1.00 \mathrm{E}+00$ & $6.95 \mathrm{E}-03$ & $1.00 \mathrm{E}+00$ & $7.28 \mathrm{E}-02$ & $1.00 \mathrm{E}+00$ & $1.00 \mathrm{E}+00$ \\
\hline Arp2-3 & $1.00 \mathrm{E}+00$ & I.5IE-0| & $3.95 \mathrm{E}-0 \mathrm{I}$ & $1.00 \mathrm{E}+00$ & $5.56 \mathrm{E}-0 \mathrm{O}$ & $1.00 \mathrm{E}+00$ & $5.00 \mathrm{E}-0 \mathrm{I}$ & $1.00 \mathrm{E}+00$ \\
\hline ATP_FO & $1.00 \mathrm{E}+00$ & $9.68 \mathrm{E}-0 \mathrm{I}$ & $9.53 \mathrm{E}-0 \mathrm{I}$ & $6.30 \mathrm{E}-0 \mathrm{I}$ & $8.03 \mathrm{E}-01$ & $1.00 \mathrm{E}+00$ & $2.2 \mathrm{IE}-03$ & $3.29 \mathrm{E}-03$ \\
\hline ATP_FI & $1.00 \mathrm{E}+00$ & $6.43 \mathrm{E}-0 \mathrm{I}$ & $1.00 \mathrm{E}+00$ & $4.92 \mathrm{E}-0 \mathrm{I}$ & $1.00 \mathrm{E}+00$ & $1.00 \mathrm{E}+00$ & 6.77E-0I & $1.00 \mathrm{E}+00$ \\
\hline APC & $2.14 \mathrm{E}-0 \mid$ & $7.26 \mathrm{E}-0 \mathrm{I}$ & $6.65 \mathrm{E}-0 \mathrm{I}$ & 2.07E-0I & $7.28 \mathrm{E}-0 \mathrm{I}$ & $8.60 \mathrm{E}-0 \mathrm{I}$ & $6.95 \mathrm{E}-02$ & $7.16 \mathrm{E}-0 \mathrm{I}$ \\
\hline $\operatorname{cox}$ & $1.00 \mathrm{E}+00$ & $7.26 \mathrm{E}-0 \mathrm{I}$ & $3.54 \mathrm{E}-0 \mathrm{I}$ & $1.00 \mathrm{E}+00$ & $3.43 \mathrm{E}-0 \mathrm{I}$ & $1.00 \mathrm{E}+00$ & $2.20 \mathrm{E}-0 \mathrm{I}$ & $1.96 \mathrm{E}-06$ \\
\hline Centrosome & $7.58 \mathrm{E}-0 \mathrm{I}$ & $9.13 \mathrm{E}-01$ & $9.90 \mathrm{E}-0 \mathrm{I}$ & $5.96 \mathrm{E}-0 \mathrm{I}$ & 7.IIE-02 & 7.27E-02 & I.46E-0| & I.79E-03 \\
\hline Dynactin & $9.26 \mathrm{E}-01$ & $1.00 \mathrm{E}+00$ & $8.82 \mathrm{E}-0 \mathrm{I}$ & 7.94E-0I & $6.80 \mathrm{E}-0 \mathrm{I}$ & $8.21 \mathrm{IE}-0 \mathrm{I}$ & $3.50 \mathrm{E}-02$ & $2.35 \mathrm{E}-0 \mathrm{I}$ \\
\hline Exocyst & $6.93 \mathrm{E}-01$ & $3.32 \mathrm{E}-0 \mathrm{I}$ & 5.87E-0I & $3.44 \mathrm{E}-02$ & $6.80 \mathrm{E}-0 \mathrm{I}$ & I.8IE-0I & $3.85 \mathrm{E}-0 \mathrm{I}$ & $2.35 \mathrm{E}-0 \mathrm{I}$ \\
\hline Exosome & $8.44 \mathrm{E}-0 \mathrm{I}$ & $8.20 \mathrm{E}-0 \mathrm{I}$ & $3.95 \mathrm{E}-0 \mathrm{I}$ & $1.00 \mathrm{E}+00$ & $1.00 \mathrm{E}+00$ & $1.00 \mathrm{E}+00$ & I.82E-0| & $3.62 \mathrm{E}-0 \mathrm{I}$ \\
\hline FA & $3.81 \mathrm{E}-0 \mathrm{I}$ & $6.38 \mathrm{E}-0 \mathrm{I}$ & I.49E-0I & 7.64E-02 & $9.37 \mathrm{E}-01$ & $1.27 \mathrm{E}-0 \mathrm{I}$ & I.2|E-0| & $1.53 \mathrm{E}-0 \mathrm{I}$ \\
\hline GTC & $6.02 \mathrm{E}-0 \mathrm{I}$ & $8.73 \mathrm{E}-0 \mathrm{I}$ & 4.97E-0I & 7.4IE-0I & $2.24 \mathrm{E}-0 \mathrm{I}$ & $3.89 \mathrm{E}-0 \mathrm{I}$ & 6.IOE-0I & $4.90 \mathrm{E}-0 \mathrm{I}$ \\
\hline LRS & $9.99 \mathrm{E}-01$ & $8.14 \mathrm{E}-0 \mathrm{I}$ & $9.96 \mathrm{E}-0 \mathrm{I}$ & $9.83 \mathrm{E}-0 \mathrm{I}$ & $9.46 \mathrm{E}-0 \mathrm{I}$ & $1.00 \mathrm{E}+00$ & 4.42E-04 & 2.79E-07 \\
\hline MLRS & $9.26 \mathrm{E}-0 \mathrm{I}$ & $6.68 \mathrm{E}-0 \mathrm{I}$ & $6.69 \mathrm{E}-0 \mathrm{I}$ & 4.78E-0I & 4.17E-02 & $9.74 \mathrm{E}-0 \mathrm{I}$ & I.IIE-04 & 9.4 IE-0I \\
\hline MSRS & $9.40 \mathrm{E}-0 \mathrm{I}$ & $2.33 \mathrm{E}-0 \mathrm{I}$ & $2.47 \mathrm{E}-0 \mathrm{I}$ & $5.82 \mathrm{E}-0 \mathrm{I}$ & $9.52 \mathrm{E}-0 \mathrm{I}$ & $9.73 \mathrm{E}-0 \mathrm{I}$ & $3.1 \mathrm{IE}-04$ & $6.32 \mathrm{E}-03$ \\
\hline Nucleopore & $3.14 \mathrm{E}-0 \mid$ & $3.68 \mathrm{E}-0 \mathrm{I}$ & $1.40 \mathrm{E}-0 \mathrm{I}$ & 8.82E-0I & $9.92 \mathrm{E}-0 \mathrm{I}$ & $3.24 \mathrm{E}-0 \mathrm{I}$ & I.13E-03 & $3.60 \mathrm{E}-0 \mathrm{I}$ \\
\hline Nucleosome & $9.91 \mathrm{E}-01$ & $8.62 \mathrm{E}-03$ & 9.7IE-0I & $3.53 \mathrm{E}-0 \mathrm{I}$ & $8.94 \mathrm{E}-0 \mathrm{I}$ & $9.79 \mathrm{E}-0 \mathrm{I}$ & $3.28 \mathrm{E}-0 \mathrm{I}$ & $4.46 \mathrm{E}-33$ \\
\hline ORC & $2.75 \mathrm{E}-0 \mathrm{I}$ & $8.73 \mathrm{E}-0 \mathrm{I}$ & $8.40 \mathrm{E}-0 \mathrm{I}$ & I.0IE-0I & $6.23 \mathrm{E}-0 \mathrm{I}$ & $3.89 \mathrm{E}-0 \mathrm{I}$ & $1.00 \mathrm{E}+00$ & $1.00 \mathrm{E}+00$ \\
\hline PD & $6.93 \mathrm{E}-0 \mathrm{I}$ & $9.10 \mathrm{E}-01$ & $8.33 \mathrm{E}-02$ & $4.28 \mathrm{E}-0 \mathrm{I}$ & $6.80 \mathrm{E}-0 \mathrm{I}$ & $4.73 \mathrm{E}-0 \mathrm{I}$ & 7.00E-0I & 6.IIE-0I \\
\hline Proteasome & $6.03 \mathrm{E}-01$ & $9.96 \mathrm{E}-0 \mathrm{I}$ & $4.02 \mathrm{E}-0 \mathrm{I}$ & $9.62 \mathrm{E}-0 \mathrm{I}$ & $6.92 \mathrm{E}-0 \mathrm{I}$ & $1.00 \mathrm{E}+00$ & $5.18 \mathrm{E}-08$ & I.99E-03 \\
\hline RFC & $3.67 \mathrm{E}-0 \mathrm{I}$ & $1.00 \mathrm{E}+00$ & $2.84 \mathrm{E}-0 \mathrm{I}$ & I.84E-0I & I.I0E-0I & $6.26 \mathrm{E}-0 \mathrm{I}$ & $1.00 \mathrm{E}+00$ & $1.00 \mathrm{E}+00$ \\
\hline RNA Pol II & $6.45 \mathrm{E}-0 \mathrm{I}$ & $5.92 \mathrm{E}-0 \mathrm{I}$ & 4.79E-03 & $1.00 \mathrm{E}+00$ & $1.00 \mathrm{E}+00$ & $1.00 \mathrm{E}+00$ & $3.88 \mathrm{E}-0 \mathrm{I}$ & $8.68 \mathrm{E}-0 \mathrm{I}$ \\
\hline RNA Pol III & $8.44 \mathrm{E}-0 \mathrm{I}$ & $1.00 \mathrm{E}+00$ & $3.95 \mathrm{E}-0 \mathrm{I}$ & $2.66 \mathrm{E}-0 \mathrm{I}$ & $1.00 \mathrm{E}+00$ & $7.28 \mathrm{E}-02$ & $8.48 \mathrm{E}-0 \mathrm{I}$ & $1.00 \mathrm{E}+00$ \\
\hline SNARE & $9.26 \mathrm{E}-0 \mathrm{I}$ & I.I4E-0I & 5.87E-0I & 7.94E-0I & $2.83 \mathrm{E}-0 \mathrm{I}$ & $4.73 \mathrm{E}-0 \mathrm{I}$ & $9.29 \mathrm{E}-0 \mathrm{I}$ & 6.IIE-0I \\
\hline SWI-SNF & $5.40 \mathrm{E}-0 \mathrm{I}$ & $9.04 \mathrm{E}-01$ & $3.92 \mathrm{E}-0 \mathrm{I}$ & $9.33 \mathrm{E}-0 \mathrm{I}$ & $1.00 \mathrm{E}+00$ & 7.73E-0I & $3.14 \mathrm{E}-0 \mathrm{I}$ & $7.92 \mathrm{E}-0 \mathrm{I}$ \\
\hline SRP & $9.19 \mathrm{E}-02$ & 7.47E-0I & $7.05 \mathrm{E}-0 \mathrm{I}$ & $1.00 \mathrm{E}+00$ & $1.00 \mathrm{E}+00$ & $6.26 \mathrm{E}-0 \mathrm{I}$ & $9.47 \mathrm{E}-02$ & $1.00 \mathrm{E}+00$ \\
\hline SCF & $6.72 \mathrm{E}-0 \mathrm{I}$ & $6.43 \mathrm{E}-0 \mathrm{I}$ & $6.00 \mathrm{E}-0 \mathrm{I}$ & $1.00 \mathrm{E}+00$ & $3.86 \mathrm{E}-0 \mathrm{I}$ & $1.00 \mathrm{E}+00$ & 3.10E-02 & $1.00 \mathrm{E}+00$ \\
\hline SRS & $9.94 \mathrm{E}-0 \mathrm{I}$ & $2.00 \mathrm{E}-0 \mathrm{I}$ & $2.57 \mathrm{E}-0 \mathrm{I}$ & $9.33 \mathrm{E}-0 \mathrm{I}$ & $5.95 \mathrm{E}-0 \mathrm{I}$ & $9.93 \mathrm{E}-0 \mathrm{I}$ & 7.69E-03 & I.67E-II \\
\hline TAFIID & $8.20 \mathrm{E}-0 \mathrm{I}$ & $3.18 \mathrm{E}-01$ & $9.81 \mathrm{E}-0 \mathrm{I}$ & 5.05E-0I & $3.08 \mathrm{E}-0 \mathrm{I}$ & $1.00 \mathrm{E}+00$ & $1.96 \mathrm{E}-0 \mathrm{I}$ & $4.49 \mathrm{E}-0 \mathrm{I}$ \\
\hline TRAPP & $6.02 \mathrm{E}-0 \mathrm{I}$ & $8.73 \mathrm{E}-0 \mathrm{I}$ & $1.00 \mathrm{E}+00$ & $7.4 \mid \mathrm{E}-0 \mathrm{I}$ & $6.23 \mathrm{E}-0 \mathrm{I}$ & $1.00 \mathrm{E}+00$ & $2.82 \mathrm{E}-0 \mathrm{I}$ & $1.00 \mathrm{E}+00$ \\
\hline VHL & $1.00 \mathrm{E}+00$ & $1.00 \mathrm{E}+00$ & $2.84 \mathrm{E}-0 \mathrm{I}$ & $1.00 \mathrm{E}+00$ & $1.00 \mathrm{E}+00$ & $1.00 \mathrm{E}+00$ & $3.73 \mathrm{E}-0 \mathrm{I}$ & $1.00 \mathrm{E}+00$ \\
\hline
\end{tabular}

$P$ values obtained with the expression peaks method in each time interval of the cell-cycle or with Pearson correlation coefficient throughout the cell-cycle. AP2, adaptor-related protein complex 2; APC, anaphase promoting complex; ARC, axin related complex; ATP_FO, ATP synthase, H+ transporting, mitochondrial F0 complex; ATP_FI, ATP synthase, $\mathrm{H}+$ transporting, mitochondrial FI complex; COX, cytochrome c oxidase; FA, focal adhesion; GTC, golgi transport complex; MSRS, mitochondrial small ribosomal subunit; ORC, origin recognition complex; PD, pyruvate dehydrogenase; RNA Pol II, RNA polymerase II; SRP, signal recognition particle; TRAPP, trafficking protein particle complex; VHL, von Hippel-Lindau complex.

interval in which the genes of the complex peaked synchronously with the best $p$ value (see below). To exclude that the number of synchronously peaking genes had been obtained by chance, we performed the same analysis on the Pearson's case described above by using a hypergeometric test. Among the 32 protein complexes analyzed, 14 in Thy-Thy2, 13 in ThyThy 3 and 13 in Thy-Noc showed a $p$ value lower than 0.05 in at least one time interval along the cell-cycle. As stable com- plexes we detected the mitochondrial large ribosomal subunit (MLRS), SRS, the proteasome and RNA polymerase II. Interestingly, low $p$ values appeared for a large number of transient protein complexes in all three datasets; dynactin, exocyst, the nucleosome, the replication complex (RFC) and the skp1-cull-F-box complex (SCF) are transient complexes with a significant $p$ value in two out of three datasets (Table 2 for the Thy-Noc dataset, and Additional data file 1 for the Thy- 
Table 3

\begin{tabular}{|c|c|c|c|c|c|c|c|}
\hline \multirow[b]{2}{*}{ Protein complex } & \multicolumn{7}{|c|}{ Peaks of expression (\% of peaking genes per complex) } \\
\hline & $2 \mathrm{~h}-0 \mathrm{~h}$ & $4 \mathrm{~h}-2 \mathrm{~h}$ & $6 \mathrm{~h}-4 \mathrm{~h}$ & $8 \mathrm{~h}-6 \mathrm{~h}$ & $10 \mathrm{~h}-8 \mathrm{~h}$ & $12 \mathrm{~h}-10 \mathrm{~h}$ & $14 \mathrm{~h}-12 \mathrm{~h}$ \\
\hline AP2 & 50 & 25 & 25 & 0 & 25 & 25 & 50 \\
\hline ARC & 80 & 0 & 0 & 80 & 0 & 60 & 0 \\
\hline Arp2-3 & 0 & 60 & 40 & 0 & 20 & 0 & 40 \\
\hline ATP_F0 & 0 & 10 & 10 & 20 & 10 & 0 & 80 \\
\hline ATP_FI & 0 & 33 & 0 & 33 & 0 & 0 & 33 \\
\hline APC & 50 & 25 & 25 & 38 & 13 & 13 & 63 \\
\hline $\operatorname{cox}$ & 0 & 25 & 38 & 0 & 25 & 0 & 50 \\
\hline Centrosome & 27 & 22 & 14 & 20 & 24 & 31 & 39 \\
\hline Dynactin & 14 & 0 & 14 & 14 & 14 & 14 & 71 \\
\hline Exocyst & 29 & 43 & 29 & 57 & 14 & 43 & 43 \\
\hline Exosome & 20 & 20 & 40 & 0 & 0 & 0 & 60 \\
\hline FA & 34 & 28 & 34 & 30 & 9 & 30 & 40 \\
\hline GTC & 33 & 17 & 33 & 17 & 33 & 33 & 33 \\
\hline LRS & 6 & 22 & 6 & 6 & 6 & 0 & 72 \\
\hline MLRS & 22 & 27 & 24 & 22 & 27 & 11 & 62 \\
\hline MSRS & 20 & 37 & 33 & 20 & 7 & 10 & 63 \\
\hline Nucleopore & 37 & 33 & 37 & 13 & 3 & 27 & 60 \\
\hline Nucleosome & 13 & 54 & 13 & 25 & 8 & 8 & 38 \\
\hline ORC & 50 & 17 & 17 & 50 & 17 & 33 & 0 \\
\hline PD & 29 & 14 & 57 & 29 & 14 & 29 & 29 \\
\hline Proteasome & 30 & 9 & 30 & 9 & 13 & 0 & 87 \\
\hline RFC & 50 & 0 & 50 & 50 & 50 & 25 & 0 \\
\hline RNA Pol II & 30 & 30 & 70 & 0 & 0 & 0 & 40 \\
\hline RNA Pol III & 20 & 0 & 40 & 40 & 0 & 60 & 20 \\
\hline SNARE & 14 & 57 & 29 & 14 & 29 & 29 & 14 \\
\hline SWI-SNF & 33 & 17 & 33 & 8 & 0 & 17 & 42 \\
\hline SRP & 75 & 25 & 25 & 0 & 0 & 25 & 75 \\
\hline SCF & 33 & 33 & 33 & 0 & 33 & 0 & 100 \\
\hline SRS & 10 & 40 & 35 & 10 & 15 & 5 & 60 \\
\hline TAFIID & 23 & 38 & 8 & 23 & 23 & 0 & 46 \\
\hline TRAPP & 33 & 17 & 0 & 17 & 17 & 0 & 50 \\
\hline VHL & 0 & 0 & 50 & 0 & 0 & 0 & 50 \\
\hline
\end{tabular}

For each protein complex the percentage of its synchronously peaking genes in each time interval is reported. AP2, adaptor-related protein complex 2; APC, anaphase promoting complex; ARC, axin related complex; ATP_FO, ATP synthase, $\mathrm{H}+$ transporting, mitochondrial F0 complex; ATP_FI, ATP synthase, $\mathrm{H}+$ transporting, mitochondrial FI complex; COX, cytochrome c oxidase; FA, focal adhesion; GTC, golgi transport complex; MSRS, mitochondrial small ribosomal subunit; ORC, origin recognition complex; PD, pyruvate dehydrogenase; RNA Pol II, RNA polymerase II; SRP, signal recognition particle; TRAPP, trafficking protein particle complex; VHL, von Hippel-Lindau complex.

Thy datasets). Another remarkable difference with respect to the Pearson-based method is that we never found complexes with a $p$ value $\geq 0.7$.

\section{The expression peaks method displays a higher} sensitivity compared to Pearson correlation coefficient To assess the quality of the expression peaks method in finding co-regulated genes that encode interacting proteins, we estimated false discovery rates (FDRs; see Materials and methods, and Additional data file 2). We plotted the FDRs for the Pearson correlation coefficient and the expression peaks methods as a function of the Bonferroni corrected $p$ value (Figure 1). The results from the Thy-Noc dataset (Figure 1) indicate an additional benefit of the expression peaks method. Clearly, for each $p$ value, the expression peaks method displayed a smaller FDR than the Pearson method. In particular, the $p$ value that corresponds to a 10\% FDR for the expression peaks method $\left(p=0.1\right.$, that is, $\log _{10}(p$ value $\left.)=1\right)$ corresponds to a 30\% FDR for the Pearson's method.

Furthermore, we also compared the sensitivity of the Pearson and expression peaks methods (Figure 2). At a fixed FDR, the 


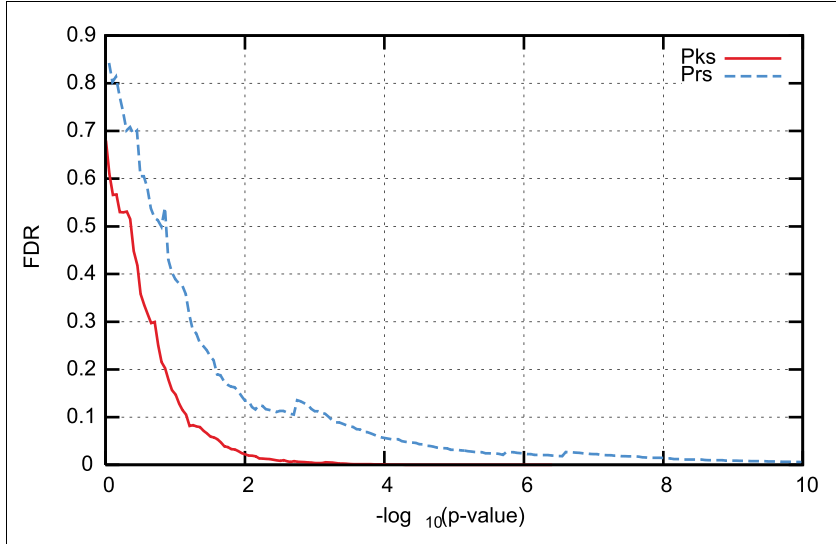

Figure I

Comparison of the FDRs for the Pearson correlation coefficient (Prs) and expression peaks (Pks) methods as a function of $p$ value. For the Thy-Noc HeLa cell-cycle dataset, estimated FDRs ( $y$-axis) are reported as a function of the Bonferroni corrected $p$ value ( $x$-axis).

number of identified real complexes using either of the two methods was assessed. For the Thy-Thy datasets, with a low FDR, the Pearson's coefficient had a higher sensitivity in detecting high co-regulation among components of the same complex, while the expression peaks method clearly performed better across the different FDR ranges for the ThyNoc dataset and at high FDRs for the Thy-Thy datasets.

The Pearson's coefficient analysis and the expression peaks method were also used to study protein complexes in additional time series datasets analyzing non-synchronized HeLa cells subjected to several stresses [25]. Similar sensitivity for both synchronized and non-synchronized cells were obtained with the former method, while, as expected, the latter was more powerful in analyzing synchronized cells. Figure 3 and Additional data file 4 show the sensitivity of both methods for non-synchronized cells.

\section{PEGO: a web based computational tool that combines the expression peaks method with Gene Ontology annotations}

To improve the ability of the expression peaks method to identify new putative interactors of given genes, our approach was combined with an extensive GO annotation analysis. We developed a web based tool named PEGO (Peaks Expression and Gene Ontology) [26] to provide public access to such an analysis. PEGO selects two groups of genes; the first contains all the genes that have the same expression peak pattern as the input genes while the second includes all the genes with the same GO categories as the input. The user can then intersect the two sets of genes to identify the putative interacting proteins in their input dataset. Moreover, the tool allows the output data to be restricted, such as selecting preferred GO annotation terms or isolating a given time point in the array experiment $[19,25]$. In Additional data files 5-7 results are shown that were obtained by querying PEGO with a list of genes from a subset of the analyzed human complexes.

\section{Generation of novel interaction candidates for PAK I}

To test the predictive capability of our approach in detecting novel protein interactions, PAK1 was selected as candidate for study from the Thy-Noc dataset. PAK1 is a serine/threonine kinase implicated in the control of a number of cellular activities, including regulation of adhesive and trafficking processes, apoptosis, cell-cycle, and cytoskeletal dynamics $[27,28]$. We queried PEGO for PAK1 by using its ID [EntrezGene:5058], Organelle organization and biogenesis [GO:0006996] as the Biological process term and Cytoskeleton [GO:0005856] or Cytoplasm [GO:0005737] as the Cellular component term. According to this analysis, PAK1 was associated with three peaks. The highest percentage of genes with the same PAK1 GO annotation (Organelle organization and biogenesis) peaked in the time interval $14 \mathrm{~h}-12 \mathrm{~h}$. Among them, 106 genes also displayed Cytoskeleton or Cytoplasm GO annotation (Additional data file 8); 5 of these genes are known interactors of PAK1 [29-33], 8 are similar to actin or actin-binding proteins, 4 are tubulins or tubulin-related proteins, 28 are proteins that localize also to the nucleus and 2 are involved in endocytosis. All these data largely match the known roles of PAK1, including the F-actin binding activity [28], the regulation of microtubule dynamics [34] and the involvement in cellular trafficking $[28,35,36]$.

\section{Experimental validation}

Using the described approach, $\alpha$-tubulin and EEA1 were selected as new interacting partners of PAK1 to be experimentally validated in living mammalian cells. Using immunoprecipitation assays, we detected the physical interaction between endogenous PAK1 and $\alpha$-tubulin in HeLa cells (Figure 4, and Additional data file 9).

It is known that both PAK1 and EEA1 are involved in growth factor stimulated [36,37] macropinocytosis [38] and that PAK1 localizes to ruffling F-actin areas where macropinosomes form [28,39,40]. Therefore, to investigate the interaction between PAK1 and EEA1, murine embryo fibroblasts (MEFs) were stimulated with platelet-derived growth factor (PDGF) to produce F-actin ruffles [41,42]. Because there are no suitable antibodies for PAK-1 immunofluorescence, the MEFs were transfected with PAK-green

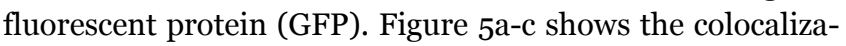
tion of PAK-GFP with endogenous EEA1 in vesicle-like structures located in ruffling areas. A similar pattern was observed also in MEFs transfected with PAK1-mRFP (data not shown) to exclude any non-specific effect the fluorescent tag may have on the colocalization.

To further demonstrate the direct interaction between PAK1 and EEA1, we screened a phage displayed peptide library with the Cdc42/Rac interactive binding (CRIB) domain of PAK1 fused to the glutathione S-transferase (GST), in the presence 


\section{(a)}

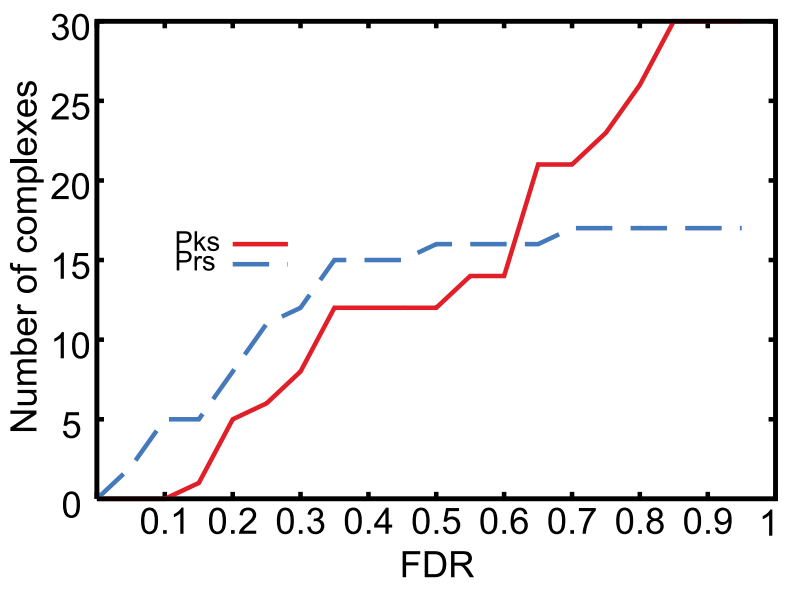

(b)

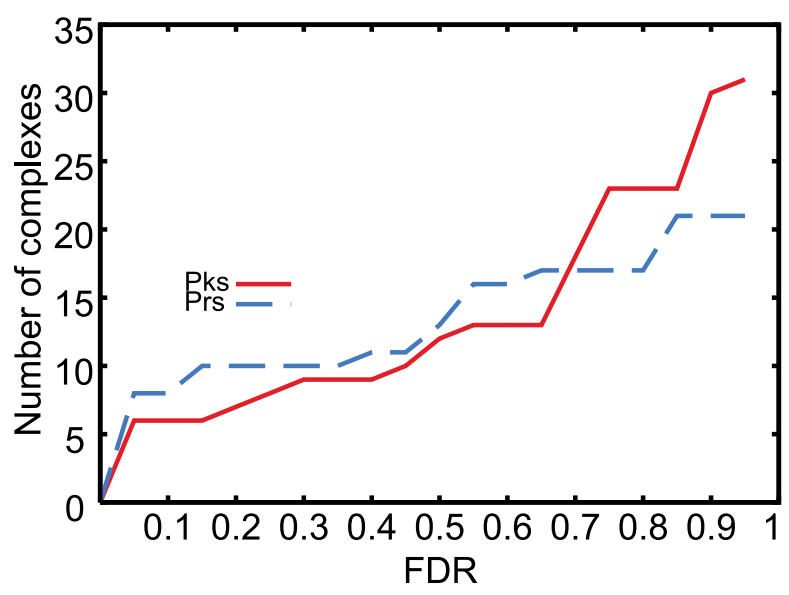

(c)

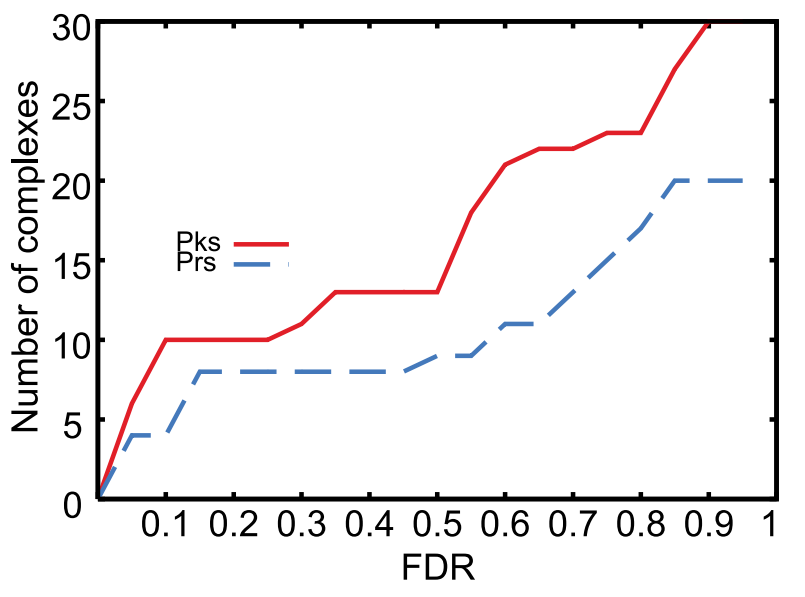

Figure 2
Figure 2

Comparison of sensitivity for the Pearson correlation coefficient (Prs) and expression peaks (Pks) methods. The number of complexes with best $p$ value equal to or lower than the corresponding one on the $\mathrm{x}$-axis is plotted for each HeLa cell-cycle dataset at a fixed FDR: (a) Thy-Thy2; (b) Thy-Thy3; (c) Thy-Noc.

of glutathione-derivatized sepharose beads. An increase in phage binding over the negative control (GST/glutathione beads) was observed after three rounds of selection. DNA sequencing revealed the presence of a peptide insert corresponding to amino acids $271-280$ of EEA1 (Figure 5 d). The specificity of this peptide was confirmed by ELISA, where its binding affinity was tested on GST-CRIB purified protein compared to GST protein alone. Figure 5e shows that the selected peptide had a specific affinity for GST-CRIB, supporting the physical association between PAK1 and EEA1.

\section{Discussion}

Identification of protein complexes by in silico analysis of the expression profiles of human genes

In this work, we propose a new method to identify proteinprotein interactions using gene expression data. The rationale behind our approach is the idea that a common transcriptional program drives the formation of both transient and permanent protein complexes in mammalian cells. It suggests that a selected gene expression dataset may contain useful information for de novo identification of protein interactions.

Because the decay rates of individual mRNAs range from 15 minutes to 24 hours [43], we focused our analysis on gene coregulation in a single time interval to reduce noise. To asses the performance of our method with respect to the standard Pearson-based one we tested both of them with a set of 32 known complexes. To avoid problems due to multiple testing, we evaluated FDRs by comparing our results with those of thousands of randomly chosen sets of genes.

The main result of our analysis is that the study of synchronous peaks of expression can successfully complement the standard Pearson-based analysis of expression data. While Pearson-based methods are more effective in the identification of permanent interactions, our method is particularly suited for transient interactions. This observation suggests that it is best to use a combination of Pearson's and expression peak analyses for computational evaluation of protein complexes.

The higher sensitivity of the expression peaks method for transient complexes seems to be connected with its ability to detect quantitatively modest but functionally important changes in gene expression, which would otherwise be missed, especially in non-synchronized cell populations. With Pearson's analysis, a high statistical significance is 
(a)

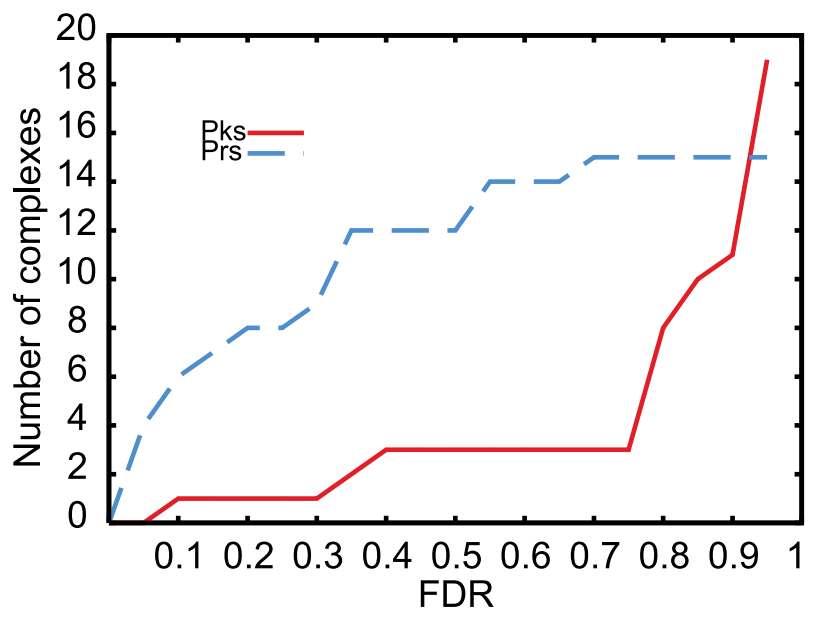

(b)

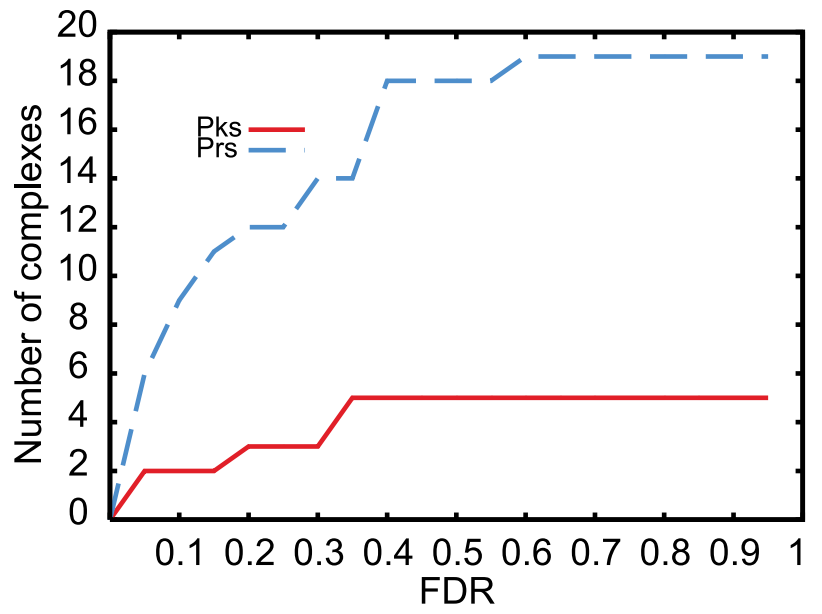

(c)

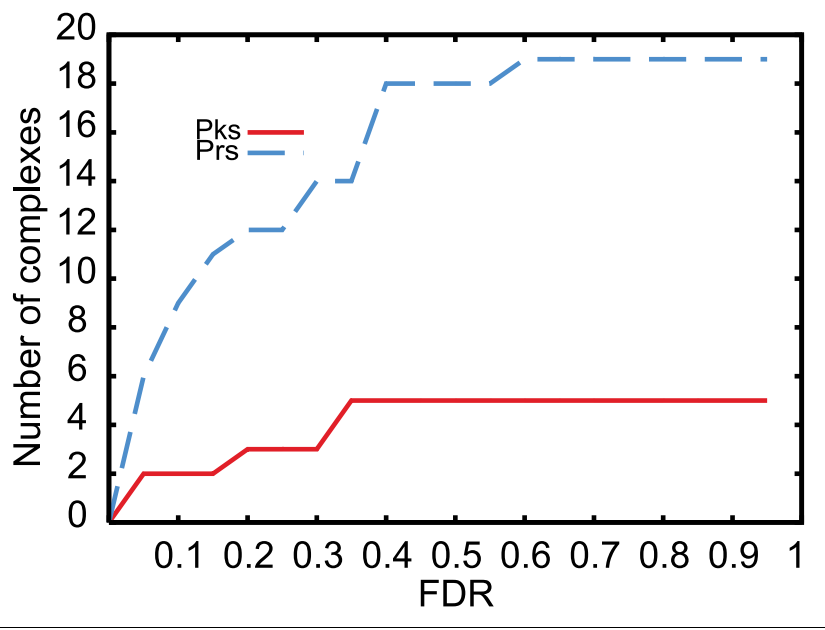

Figure 3
Figure 3

Non-synchronized HeLa cells. The number of complexes with a best $p$ value equal to or lower than the corresponding one on the $\mathrm{x}$-axis is plotted for three non-synchronized and stressed HeLa datasets at a fixed FDR: (a) dithiothreitol (DTT); (b) heat shock; (c) tunicamycin.

obtained only for a small subset of complexes. In contrast, the expression peaks method gives statistically significant results for a greater number of complexes, although with higher $p$ values than the Pearson's method.

Another important observation is that the expression peaks method performs better for well synchronized datasets (that is, the Thy-Noc treatment). On the basis of our methodological assumptions (that is, the half-life of mRNA [43]), this is not surprising as it restricts the application of this method to highly selected datasets. However, the current technical efforts to improve cell synchronization will extend the reliability of the expression peaks method to a larger number of gene expression datasets.

\section{Improvement of the expression peaks method by Gene Ontology analysis}

The analysis of co-regulation during only a single time point increases the sensitivity of the expression peaks method, but also increases the noise. We therefore combined this method with GO analysis and found that this association reduced the number of false positives generated by the exclusive use of the expression peaks method. Combining both analyses reduced the number of potential candidate interactors to a few dozen while the output lists obtained by using either one of these approaches alone contained up to a thousand genes (Additional data file 6). A similar improvement was also recently observed by Corà et al. [44], who successfully combined GO and gene expression analyses in HeLa cell-cycle datasets to extract putative co-regulated genes for the identification of candidate transcription factor binding sites.

It is worthwhile to note that in several cases not all genes of the same complex were strictly co-regulated (Table 3 , and Additional data file 3). This represents an intrinsic limitation

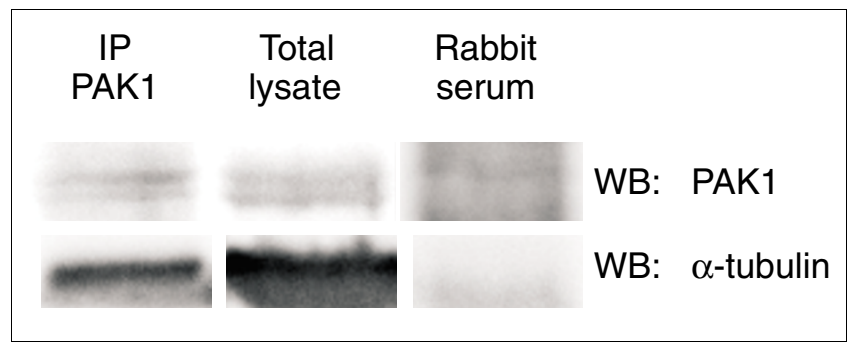

Figure 4

PAKI physically interacts with $\alpha$-tubulin. HeLa cell lysate was immunoprecipitated with anti-PAKI antibody and blotted with anti- $\alpha$ tubulin antibody. The figure is representative of three experiments obtained with similar results. 
of any approach based on gene expression data to identify protein interaction. Of course, subcellular localization, and post-transcriptional and post-translational modifications also play a key role in the assembly of both permanent and transient complexes [45-48]. Thus, the addition of further information, such as post-translational modifications, could greatly improve the quality of the results, an approach we plan to use in the future.

\section{PEGO public software}

To enable researchers to test our computational approach, we implemented our pipeline as a web-based, publicly available tool named PEGO [26], which we have queried to identify new protein interactions that we validated experimentally. It is interesting to observe that the PEGO outputs contained additional interacting partners whose genes were not included in our query list. For instance, in the case of the dynactin complex (Additional data file 6c) five new candidates emerged, and two of these, that is, non-erythrocytic spectrins, turned out to be previously characterized interactors of the dynactin complex $[49,50]$ (data not shown). While this result confirms the capability of our method to detect functional units, PEGO may actually be applied to a broader class of data types, in particular, to groups of genes without any known and obvious relationship. For example, one could analyze a list of genes that, if silenced, produce the same phenotype and use PEGO to detect any interactions among those candidates. Thus, unlike starting with a list of genes that have similar GO annotation, this approach excludes any prior bias for detection of protein-protein interactions. However, after a list of potential interactors has been generated, further GO analysis will increase the likelihood of detecting new complexes.

\section{Discovery of new interactors of PAKI by combining PEGO with 'wet' biological experiments}

The potential of PEGO has been confirmed by 'wet' biological experiments testing the in silico results obtained by submitting PAK1, as a single gene. We selected PAK1 due to our interest in cytoskeleton dynamics in vascular cells. PAK1 relates best to the GO biological process 'Organelle organization and biogenesis', because this category includes both cytoskeleton- and vesicular-related functions that fit well with the subcellular localization of PAK1 in living cells (data not shown). Among the three expression peaks of PAK1 in the Thy-Noc dataset, we selected the 14 h-12 h one because a high percentage of 'Organelle organization and biogenesis' anno- tated genes peaked there, thus suggesting a novel intriguing role of PAK1 in this process.

PEGO indicated a list of genes to be considered as potential new interactors of PAK1. In light of the PAK1-related literature, we evaluated $\alpha$-tubulin and EEA1 as potential interactors to be experimentally confirmed. Previous work showed a co-localization of microtubules and PAK1 [51] and identified tubulin cofactor B (a cofactor associating with $\alpha$ - and $\beta$-tubulin) as an interacting substrate of PAK1 [34]. These data hint at an interaction between PAK1 and $\alpha$-tubulin, although no experimental evidence has been obtained for this. We therefore used immunoprecipitation experiments in HeLa cells to demonstrate the physical interaction between PAK1 and $\alpha$ tubulin supporting the immunofluorescence co-localization data previously reported [34].

The PAK1- EEA1 interaction, however, has not been reported before, and it represents a novel finding highlighting the potential of PEGO to predict unknown protein-protein interactions. Interestingly, we observed that PAK1 and EEA1 colocalize at sites resembling large vesicular structures. This hypothesis is supported by Dharmawardane et al. [36], who described the formation of large macropinocytic vesicles lined by PAK1 in PDGF-stimulated cells. Although the colocalization at these sites suggested a functional relationship between PAK1 and EEA1, the small amounts of overlayed proteins were not sufficient to test their physical interaction by immunoprecipitation. To overcome this technical problem, we screened a phage library to find specific peptides able to bind the CRIB domain of PAK1. Besides binding the small GTPases Cdc42 and Rac1, which trigger the catalytic activity of PAK1, the CRIB domain is also known to bind other transducers [22]. The selection of a peptide encompassing an amino acid region of EEA1 (Figure 5d) clearly showed that the observed co-localization in immunofluorescence studies between EEA1 and PAK1 indeed reflects a true interaction.

\section{Future perspectives}

Our statistical approach to identify protein complexes could be improved by taking into account a greater number of microarray gene expression data obtained by in vitro experiments performed on specific models of cell activation. The same approach applied to in vivo animal models should also allow the discrimination of changes in a putative complex caused by the tissue microenvironment or during develop-

\footnotetext{
Figure 5 (see following page)

Experimental evidence for the interaction of PAKI with EEAI. Confocal analysis of the cross section (a) and the vertical section (c) of PDGF-induced MEF cell reveals that endogenous EEAI colocalized (yellow) with PAKI-GFP. (b) Quantification of the colocalization where the x-axis represents the white line in the inset (rotated $-90^{\circ}$ compared to (a)) and the $y$-axis represents the fluorescence intensity. The first peak of intensity in both channels indicates that PAKI (green) and EEAI (red) were enriched at the same site. (d) Sequence matching (computed with the multiple sequence alignment program ClustalW) obtained for the phage-display selected peptide QLRSEGPF and the aminoacidic sequence of EEAI. (e) Binding of the selected peptide (QLRSEGPF) to GST-CRIB and the negative control performed with GST alone. Binding of the insertless phage was tested with either GST or GST-CRIB, which showed no differences in affinity. The y-axis represents the absorbance (OD $450 \mathrm{~nm}$ ). Results are the mean of triplicate experiments.
} 
(a)
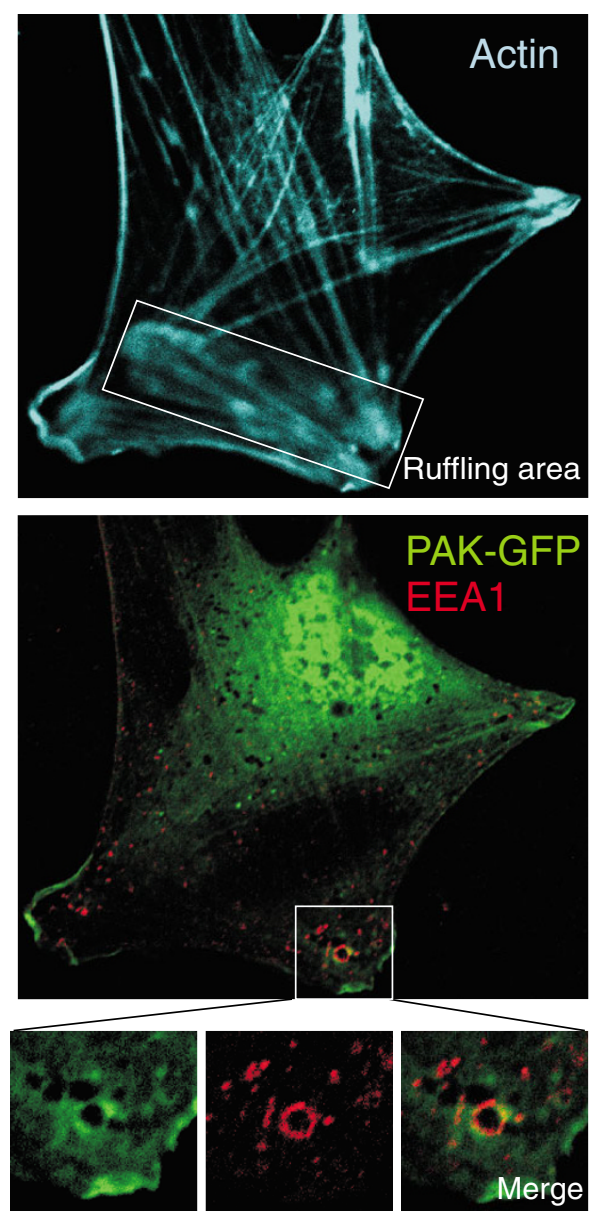

PAK-GFP EEA1
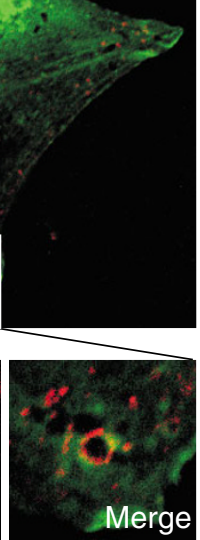

(b)
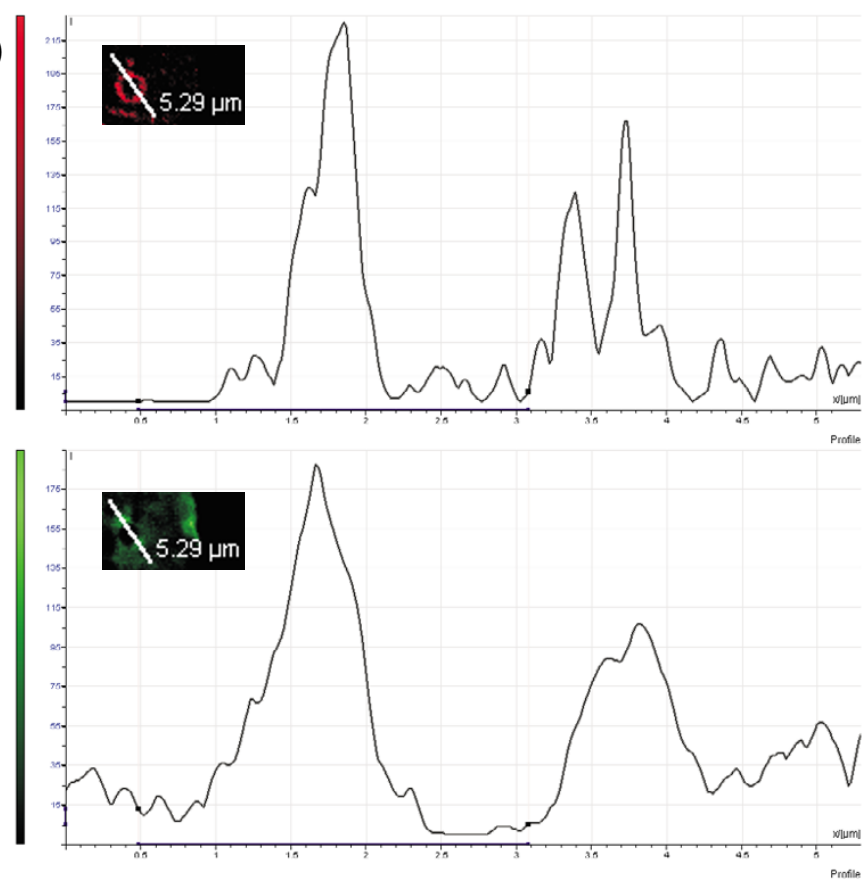

(c)
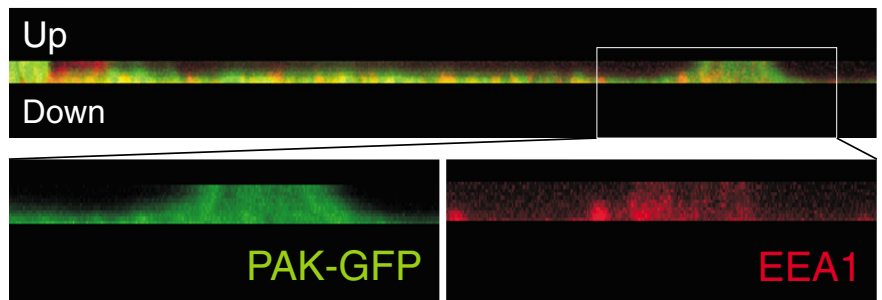

(d) peptide 1 QLRSE . - -GP . . . . - -F 7

\section{EEA1 271 QLRSELAKGPQEVAVY 280}

(e)

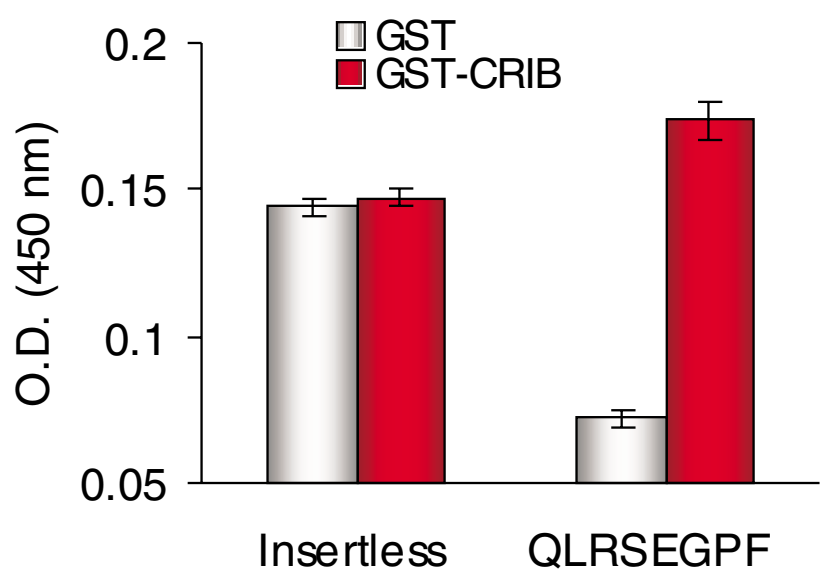

Figure 5 (see legend on previous page) 
ment. More interestingly, the comparison of microarray data obtained before and after silencing a specific gene by small RNA interference could allow the identification of new protein complexes and not just simply the identification of new interacting partners.

Finally, a further and relevant progression of our expression peaks method would be the inclusion of other information besides GO to reduce the number of false positives. This could include sequence analysis, evolutionary data or the use of the same experimental design to generate expression data from different animal species.

\section{Conclusion}

We have presented a computational methodology to statistically analyze gene expression of several known human multiprotein complexes in a single time interval. With the obtained results we developed an approach to explore novel protein interactions by studying synchronously peaking genes with similar GO annotations from microarray datasets. By applying our method to PAK1, we found five previously known interactors, confirming the validity of our approach. Next, we validated the predicted interactions with two other proteins, $\alpha$-tubulin and EEA1.

On the basis of these results, we would like to encourage researchers to use PEGO for their proteins of interest as an additional selection screen for the identification of potential interacting candidates to be experimentally validated.

\section{Materials and methods Microarray data}

We studied HeLa cell time series [19,25] from the Stanford Microarray Database [24]. The analysis was performed for every dataset separately to evaluate gene expression strictly related to specific cellular conditions. Datasets were normalized such that the Euclidean norm of each expression profile was 1 and the average was o. To evaluate changes in expression level at each step during the cell cycle, for each clone, we built a new expression vector containing differences of expression values computed between two consecutive time points. Since the HeLa cell-cycle datasets were published in 2002, we associated with all IMAGE clones new Entrez Gene IDs according to UniGene database version 183 [52], and we excluded from our analysis: clones with an ID different from the IMAGE ID or all numerical IDs; clones with more than one associated Entrez Gene ID; clones whose expression, measured as the log ratio between Cy5 (synchronous cells) and $\mathrm{Cy} 3$ (reference sample) channels, varied between -0.2 and +0.2 .

\section{Human multi-protein complexes data set}

The analyzed data set was composed of 32 permanent and transient protein complexes, in which interactions among dif- ferent components are or are not maintained, respectively [14]. Complexes were selected from the following sources: the KEGG database [53] for SRS, large ribosomal subunit (LRS), proteasome, anaphase promoting complex, von hippel-lindau complex, SCF, signal recognition particle, RNA polymerase II, RNA polymerase III, and TAFIID; NCBI [54] for trafficking protein particle complex, nucleopore, mitochondrial small ribosomal subunit, MLRS, adaptor-related protein complex 2, origin recognition complex, pyruvate dehydrogenase, ATP synthase, $\mathrm{H}+$ transporting, mitochondrial Fo complex, ATP synthase, $\mathrm{H}+$ transporting, mitochondrial $\mathrm{F} 1$ complex, and SNARE complex; literature for nucleosome [19], focal adhesion [55], centrosome [56], dynactin [57], Arp2/3 [58], exosome [59], exocyst [60], axin-related complex (ARC) [61], SWI/SNF [62], cytochrome c oxidase [63], RFC [64], and golgi transport complex [65]. To each protein the corresponding Entrez Gene ID was assigned according to UniGene database, version 183 [52] (Additional data files 10 and 11).

\section{Analysis of multi-protein complexes by Pearson coefficient}

We evaluated the gene expression correlation between clone ID pairs of genes using the Pearson Coefficient, $r$ :

$$
r=\frac{\sum_{i=1}^{n}\left(x_{i}-\bar{x}\right)\left(y_{i}-\bar{y}\right)}{\sqrt{\sum_{i=1}^{n}\left(x_{i}-\bar{x}\right)^{2} \sum_{i=1}^{n}\left(y_{i}-\bar{y}\right)^{2}}}
$$

where $\left(x_{1} \ldots x_{n}\right)$ is the expression profile vector of clone $x$, $\left(y_{1} \ldots y_{n}\right)$ is the expression profile vector of clone $y, n$ is the number of time points in the analyzed dataset:

$$
\bar{x}=\frac{1}{n} \sum_{i=1}^{n} x_{i}, \bar{y}=\frac{1}{n} \sum_{i=1}^{n} y_{i}
$$

and $r$ is the normalized scalar product of two vectors with its value being in the range $[-1,+1]$.

From the cumulative distribution of all the Pearson coefficients, we extracted the pairs of 'highly correlated' clones setting a threshold, $P_{\text {cutoff }}$, having at its right $1 \%$ of the distribution. To define the number of highly correlated genes in each protein complex, we counted pairs containing both clone IDs corresponding to genes (according to their Entrez Gene ID) of the same complex. Pairs that appeared more than one time were counted only once and pairs containing single gene information (both clone IDs with the same Entrez Gene ID) were excluded. The probability that the number of gene pairs for each complex was recovered by chance was evaluated using the hypergeometric distribution: 


$$
P_{c}=\sum_{x=f_{c}}^{M} \frac{\left(\begin{array}{l}
M \\
x
\end{array}\right)\left(\begin{array}{l}
N-M \\
n_{c}-x
\end{array}\right)}{\left(\begin{array}{l}
N \\
n_{c}
\end{array}\right)}
$$

where the index $c$ runs over all the complexes we studied, $N$ is the number of all gene pairs in the dataset, $M$ is the number of genes pairs with $r$ above $P_{\text {cutoff, }}, n_{c}$ is the number of all gene pairs in the analyzed complex, $c, f_{c}$ is the number of gene pairs in complex $c$, with $r$ above $1 \% P_{\text {cutoff }}$.

To evaluate if a different threshold of the Pearson coefficient could be useful to extract a larger and statistically significant number of highly correlated gene pairs for protein complexes, we performed Pearson analysis as described above with different $P_{\text {cutoff }}$. We found essentially no dependence of results on $P_{\text {cutoff }}$ and, therefore, used the standard value of $1 \%$ of the right tail of the Pearson coefficient distribution as threshold (data not shown).

\section{False discovery rate for Pearson coefficient analysis}

We estimated a FDR for each $p$ value, $P_{c}$, by estimating the probability that the result obtained is a false positive. We performed 3,000 randomization cycles. For each cycle we generated a set composed of the same number of genes per complex as those analyzed, but randomly selected from the dataset. For each random set we calculated its $p$ values, $p$, as described above. Then, we counted the number of real complexes, $n\left(p^{\prime \prime}\right)$, or random complexes, $r\left(p^{\prime \prime}\right)$ with a $p$ value better than $p^{\prime \prime}$. In the random case we computed the average number over all the randomizations. For each $p$ " we defined the FDR as:

$$
\operatorname{FDR}(p ")=\frac{r\left(p^{\prime}\right)}{n(p ")}
$$

Complexes composed of less than three components (that is, with a number of genes lower than three in the analyzed dataset) were not considered.

\section{Definition of expression peak}

We defined a threshold on computed differences of gene expression between consecutive time points, indicating the value over which the increase of gene expression has to be considered an expression peak. Since we worked on datasets with time intervals of different lengths (one hour for the ThyThy datasets or two hours for the Thy-Noc dataset) and number, for each dataset separately, we analyzed the distribution of all computed differences and we selected that value that has at its right $20 \%$ of the distribution.

According to different stoichiometric features of protein complexes, the transcriptional machinery may produce different amounts of specific transcripts. Actually, the stoichiometric ratios of most complexes are still unknown [66,67]. To tackle this problem by a computational method, we changed all expression values to a binary 1-o system [68]. Therefore, a new dataset matrix was generated where we substituted differences with ' 1 ' if corresponding to a peak of expression, or with 'o' otherwise.

In order to test the dependence of our results on the $20 \%$ threshold, we performed expression peaks analysis on protein complexes using different thresholds and then compared the corresponding distributions of best $p$ values. The results turned out to be largely independent from the chosen threshold, thus showing that our results are not biased by our threshold choice (data not shown).

\section{Definition of expression peak at gene level}

To apply our method of analysis to a single gene of interest using the PEGO tool, for each gene a single pattern of peaks along the cell cycle was assigned, grouping data for clones annotated to the same Entrez Gene ID. First, we defined the maximum number of peaks, $m$, that could be associated with each gene by assuming that each clone has a single significant peak of expression, and we then evaluated $m$ as the mean number of clones per gene considering all genes in the dataset. For each gene, in every interval, we summed the differences in expression levels of all its clones to obtain a single value and we selected only the $m$ higher sums. By computing the sum, the noise due to the discrepancy among values of clones of the same gene was eliminated. Finally, to rebuild the 1-o matrix, we transformed each of the $m$ sums into ' 1 ', peak of expression, if it was large enough compared to the distribution of all differences in expression level computed for clones in the dataset (that is, if the value falls in the $20 \%$ tail of the distribution). All other values were replaced with 'o'.

\section{Analysis of multi-protein complexes by the expression peaks method}

To define synchronous peaks of expression, for each complex, $c$, in each interval, $i$, we counted the number of peaking genes, $f_{i c}$. Then we evaluated the probability, $P_{i c}$, to obtain $f_{i c}$ by chance through the hypergeometric distribution:

$$
P_{i c}=\sum_{x=f_{i c}}^{M i} \frac{\left(\begin{array}{l}
M_{i} \\
x
\end{array}\right)\left(\begin{array}{l}
N-M_{i} \\
n_{c}-x
\end{array}\right)}{\left(\begin{array}{l}
N \\
n_{c}
\end{array}\right)}
$$

where $N$ is the number of genes in the analyzed dataset, $M_{i}$ is the number of genes in the analyzed dataset that peak in a selected interval $I, n_{c}$ is the number of genes of a selected protein complex $c$ in the analyzed dataset, and $f_{i c}$ is the number of genes of the selected protein complex $c$ that peak in $i . P_{i c}$ represents the probability to obtain by chance at least $f_{i c}$ peaking genes, selecting randomly in the dataset a number of genes equal to that of the analyzed protein complex. 
In order to compare (Figure 1) this definition of $p$ value with that introduced in the previous section for the Pearson's method, the present $p$ value has to be corrected for multiple testing. The standard Bonferroni procedure was performed by multiplying for the number of tested intervals (seven in the Thy-Noc dataset).

False discovery rate for the expression peaks method In order to estimate the FDR, we calculated for each random complex (generated as described for the Pearson method) the $p$ value as discussed in the previous section and we counted the number of complexes, both in the real, $n\left(p^{\prime \prime}\right)$, and in the random, $r\left(p^{\prime \prime}\right)$, cases, that had a time interval with the best $p$ value better than $p$ ". For random complexes, we considered the average number $r\left(p^{\prime \prime}\right)$ computed over all randomizations. For each $p$ " we defined the FDR according to equation 3 .

\section{Immunoprecipitation assay}

Quiescent HeLa cells were harvested from plates by addition of $500 \mu \mathrm{l}$ ice-cold lysis buffer containing $1 \%$ Triton X-100/100 $\mathrm{mm}$ dish. The cell lysates were pre-cleared with pre-immune rabbit serum and 50\% (v/v) protein G-Sepharose (Amersham Biosciences, Piscataway, NJ, USA) for $2 \mathrm{~h}$ at $4^{\circ} \mathrm{C}$ and were then incubated with $50 \%(\mathrm{v} / \mathrm{v})$ protein $\mathrm{G}-S e p h a r o s e$ and antiPAK1 (rabbit polyclonal; Cell Signaling Technology, Beverly, MA, USA) for $2 \mathrm{~h}$ at $4^{\circ} \mathrm{C}$. The immunoprecipitates were recovered and washed three times with lysis buffer. The washed immunoprecipitates were resuspended in $25 \mu \mathrm{l} 2 \times$ Laemli sample buffer and analyzed by SDS-PAGE and western blotting using anti- $\alpha$-tubulin (mouse monoclonal, clone B-5-1-2, Sigma) and anti-PAK1.

\section{Confocal analysis}

MEFs were transfected (Fugene, Roche, Basel, Switzerland) with either PAK1-GFP (a gift from Dr G Bokoch, The Scripps Research Institute, La Jolla, California) or PAK1 tagged with the monomeric red fluorescent protein, PAK1-mRFP, (Additional data file 12). Twenty-four hours after transfection, cells were incubated in DMEM $0.5 \%$ fetal bovine serum for 7 hours and then stimulated with PDGF for 6 minutes. Subsequently, cells were fixed with $3.7 \%$ para-formaldheyde and permeabilized with $0.01 \%$ saponin (Sigma, St. Louis, MO, USA). Cells were incubated with goat anti-EEA1 antibody (Santa Cruz, Biotechnology, Santa Cruz, CA, USA) and then with rabbit anti-goat Alexa 555 (Invitrogen Molecular Probes, Carlsbad, CA, USA). F-actin was stained by phalloidin Alexa 633 (Invitrogen, Carlsbad, CA, USA). Images were acquired with a Leica DMIRE2 confocal microscope and the analysis was performed with Leica Confocal software.

\section{Phage-display analysis}

We pre-adsorbed $10^{10}$ transducing units (TU) of a $\mathrm{CX}_{7} \mathrm{C}(\mathrm{C}$, cysteine; $\mathrm{X}$, any amino acid residue) phage display random library on GST in the presence of glutathione-sepahrose beads in Iscove's Modified Dulbecco's Medium, IMDM, 2\% fetal calf serum (binding medium), for 1 hour at room temper- ature. The pre-cleared phage library was then incubated with GST-fused PAK1 CRIB domain [69] in the presence of glutathione-sepharose beads in binding medium for 1 hour at room temperature. After five washes, bound phage were recovered and amplified by infection of exponentially growing K91Kan Escherichia coli. Serial dilutions were plated on LB agar plates with tetracycline and kanamycin. The numbers of TU were determined by bacterial colony counting [70,71].

\section{Peptide analysis and validation}

After three rounds of selection, 20 phage clones were selected from each experiment, and the displayed peptides were deduced by sequencing the exogenous oligonucleotide inserts. For sequencing, we used the following primer: $5^{\prime}-$ CCCTCATAGTTAGCGTAACG-3'. Sequence homologies were evaluated by searching non-redundant human protein databases (Additional data file 12).

The binding specificity of the selected peptides was evaluated by ELISA. Wells of a 96-well plate were coated with $1 \mu \mathrm{g}$ of either GST or CRIB-GST in phosphate-buffered saline. We incubated $10^{8} \mathrm{TU}$ of each clone per well in binding medium for 1 hour at room temperature. After ten washes in the same medium, bound phage was stained with an anti-M13 antibody (anti-M13 bacteriophage; Sigma), detected by a secondary anti-mouse horseradish peroxidase-conjugated monoclonal antibody and quantified using the 1-Step Turbo TMB-ELISA kit (Pierce, Rockford, IL, USA).

\section{Abbreviations}

CRIB, Cdc42/Rac interactive binding; GO, gene ontology; EEA, early endosome antigen; FDR, false discovery rate; GFP, green fluorescent protein; GST, glutathione S-transferase; LRS, large ribosomal subunit; MEF, murine embryo fibroblast; MLRS, mitochondrial large ribosomal subunit; PAK, p21-activated kinase; PDGF, platelet-derived growth factor; PEGO, Peaks Expression and Gene Ontology; RFC, replication complex; SCF, skp1-cull-F-box complex; SRS, small ribosomal subunit; Thy-Noc, thymidine-nocodazole synchronized cell dataset; Thy-Thy2, thymidine-thymidine synchronized cell dataset 2; Thy-Thy3, thymidine-thymidine synchronized cell dataset 3 ; TU, transducing units.

\section{Authors' contributions}

SZ conceived the study, designed and coordinated it, performed PAK1-related analysis and experiments and drafted the manuscript. IC conceived the study, was involved in its initial coordination and design, performed phage-display peptide analysis and helped to draft the manuscript. CP performed the statistical analysis. IM performed the statistical analysis and developed the web based PEGO. SM performed phage-display experiments and helped to draft the manuscript. MC participated in the design of the project and coordination of the statistical analysis and helped to draft the 
manuscript. FB participated in the design of the project and coordination of the biological part and helped to draft the manuscript. All authors read and approved the final manuscript.

\section{Additional data files}

The following additional data are available with the online version of this paper. Additional data file 1 is a table listing $p$ values obtained from analyzing the Thy-Thy datasets with the expression peaks method or with Pearson correlation coefficient throughout the cell-cycle. Additional data file 2 is a table listing the FDR for each protein complex. Additional data file 3 is a table listing the percentages of synchronously peaking genes in the Thy-Thy2 and Thy-Thy3 datasets. Additional data file 4 is a plot representing the number of complexes with a best $p$ value equal to or lower than the corresponding one on the $\mathrm{x}$-axis for three non-synchronized and stressed HeLa datasets at a fixed FDR. Additional data file 5 is a table listing GO term and time interval with best $p$ value for a subset of the human protein complexes analyzed with PEGO. Additional data file 6 is a table listing the number of recovered components for a subset of the human protein complexes analyzed with PEGO. Additional data file 7 is a table listing the GO analysis results for a subset of the human protein complexes analyzed with PEGO. Additional data file 8 is a table listing the selected interaction candidates for PAK1. Additional data file 9 is an image showing the specificity of anti-PAK1 and anti $\alpha$-tubulin antibodies. Additional data file 10 is a table listing Entrez Gene IDs of all components of each protein complex analyzed. Additional data file 11 is a table listing the IMAGE IDs for each component of the analyzed protein complexes. Additional data file 12 contains supplemental materials and methods.

\section{Acknowledgements}

We are grateful to Carl Herrmann, Laboratoire de Genetique et Physiologie du Developpement, IBDM, CNRS/INSERM/Université de la Mediterranée, and Marco Botta, University of Turin, Department of Informatics, for the computational resources regarding Pearson analysis and gene annotation, respectively; and to Guido Serini, Andrea Bertotti, Davide Corà and Sidney Cambridge for critical reading of the manuscript. This study was supported by Associazione Italiana per la Ricerca sul Cancro (AIRC, Projects IG and MFAG), Istituto Superiore di Sanità (VI AIDS National Projects), Università degli Studi di Torino $(60 \%)$, Ministero della Salute (Ricerca Finalizzata 2004, 2005, 2006), Regione Piemonte (Progetti di Ricerca Sanitaria Finalizzata 2006; Ricerca Industriale e Sviluppo Precompetitivo, Grant PRESTO; Ricerca Scientifica Finalizzata 2004, grants AI50 and DI0), Sixth Framework Programme of European Union: Contracts LSHM-CT-2003503254 http://www.EVGN.org and LSHM-CT-2003-50325I, Fondo per gli Investimenti della Ricerca di Base (RBNE03B8KK-006). SM is a fellow of Fondazione Italiana per la Ricerca sul Cancro.

\section{References}

I. Alberts B: The cell as a collection of protein machines: preparing the next generation of molecular biologists. Cell 1998, 92:291-294.

2. Drakas $R$, Prisco M, Baserga R: A modified tandem affinity purification tag technique for the purification of protein complexes in mammalian cells. Proteomics 2005, 5:| $32-137$.
3. Gavin AC, Bosche M, Krause R, Grandi P, Marzioch M, Bauer A, Schultz J, Rick JM, Michon AM, Cruciat CM, et al.: Functional organization of the yeast proteome by systematic analysis of protein complexes. Nature 2002, 4I 5: |4|-|47.

4. Ito T, Chiba T, Ozawa R, Yoshida M, Hattori M, Sakaki Y: A comprehensive two-hybrid analysis to explore the yeast protein interactome. Proc Natl Acad Sci USA 200I, 98:4569-4574.

5. Uetz P, Giot L, Cagney G, Mansfield TA, Judson RS, Knight JR, Lockshon D, Narayan V, Srinivasan M, Pochart P, et al.: A comprehensive analysis of protein-protein interactions in Saccharomyces cerevisiae. Nature 2000, 403:623-627.

6. Giot L, Bader JS, Brouwer C, Chaudhuri A, Kuang B, Li Y, Hao YL, Ooi CE, Godwin B, Vitols $E$, et al: A protein interaction map of Drosophila melanogaster. Science 2003, 302:1727-1736.

7. Li S, Armstrong CM, Bertin N, Ge H, Milstein S, Boxem M, Vidalain PO, Han JD, Chesneau A, Hao T, et al.: A map of the interactome network of the metazoan C. elegans. Science 2004, 303:540-543.

8. Peri S, Navarro JD, Kristiansen TZ, Amanchy R, Surendranath V, Muthusamy B, Gandhi TK, Chandrika KN, Deshpande N, Suresh S, et al.: Human protein reference database as a discovery resource for proteomics. Nucleic Acids Res 2004:D497-50I.

9. Zanzoni A, Montecchi-Palazzi L, Quondam M, Ausiello G, HelmerCitterich M, Cesareni G: MINT: a Molecular INTeraction database. FEBS Lett 2002, 5 I 3:135-140.

10. Lin N, Wu B, Jansen R, Gerstein M, Zhao H: Information assessment on predicting protein-protein interactions. $B M C$ Bioinformatics 2004, 5: I54.

II. von Mering C, Krause R, Snel B, Cornell M, Oliver SG, Fields S, Bork $P$ : Comparative assessment of large-scale data sets of protein-protein interactions. Nature 2002, 4I 7:399-403.

12. Hahn A, Rahnenfuhrer J, Talwar P, Lengauer T: Confirmation of human protein interaction data by human expression data. BMC Bioinformatics 2005, 6: I I2.

13. Jansen R, Yu H, Greenbaum D, Kluger Y, Krogan NJ, Chung S, Emili A, Snyder M, Greenblatt JF, Gerstein M: A Bayesian networks approach for predicting protein-protein interactions from genomic data. Science 2003, 302:449-453.

14. Jansen R, Greenbaum D, Gerstein M: Relating whole-genome expression data with protein-protein interactions. Genome Res 2002, I 2:37-46.

15. Rhodes DR, Tomlins SA, Varambally S, Mahavisno V, Barrette T, Kalyana-Sundaram S, Ghosh D, Pandey A, Chinnaiyan AM: Probabilistic model of the human protein-protein interaction network. Nat Biotechnol 2005, 23:951-959.

16. Sprinzak E, Altuvia $\mathrm{Y}$, Margalit $\mathrm{H}$ : Characterization and prediction of protein-protein interactions within and between complexes. Proc Natl Acad Sci USA 2006, I 03: | 47| |8- | 4723.

17. Pellegrino M, Provero P, Silengo L, Di Cunto F: CLOE: identification of putative functional relationships among genes by comparison of expression profiles between two species. BMC Bioinformatics 2004, 5: 179.

18. Han JD, Bertin N, Hao T, Goldberg DS, Berriz GF, Zhang LV, Dupuy $D$, Walhout AJ, Cusick ME, Roth FP, et al.: Evidence for dynamically organized modularity in the yeast protein-protein interaction network. Nature 2004, 430:88-93.

19. Whitfield ML, Sherlock G, Saldanha AJ, Murray Jl, Ball CA, Alexander KE, Matese JC, Perou CM, Hurt MM, Brown PO, et al.: Identification of genes periodically expressed in the human cell cycle and their expression in tumors. Mol Biol Cell 2002, I 3:1977-2000.

20. de Lichtenberg U, Jensen LJ, Brunak S, Bork P: Dynamic complex formation during the yeast cell cycle. Science 2005, 307:724-727.

21. Harris MA, Clark J, Ireland A, Lomax J, Ashburner M, Foulger R, Eilbeck K, Lewis S, Marshall B, Mungall C, et al:: The Gene Ontology (GO) database and informatics resource. Nucleic Acids Res 2004:D258-26I.

22. Bokoch GM: Biology of the p2I-activated kinases. Annu Rev Biochem 2003, 72:743-78I.

23. Mills IG, Jones AT, Clague MJ: Involvement of the endosomal autoantigen EEAI in homotypic fusion of early endosomes. Curr Biol 1998, 8:881-884.

24. Stanford Microarray Database [http://genome-www5.stan ford.edu/]

25. Murray Jl, Whitfield ML, Trinklein ND, Myers RM, Brown PO, Botstein D: Diverse and specific gene expression responses to stresses in cultured human cells. Mol Biol Cell 2004, I 5:236|-2374. 
26. Peaks Expression and Gene Ontology [http://to444xl.to.infn.it/ pego]

27. Manser E, Huang HY, Loo TH, Chen XQ, Dong JM, Leung T, Lim L: Expression of constitutively active alpha-PAK reveals effects of the kinase on actin and focal complexes. Mol Cell Biol 1997, | 7: | | 29- | | 43 .

28. Dharmawardhane S, Sanders LC, Martin SS, Daniels RH, Bokoch GM Localization of p2I-activated kinase I (PAKI) to pinocytic vesicles and cortical actin structures in stimulated cells. J Cell Biol 1997, I 38: 1265-1278.

29. Weber DS, Taniyama Y, Rocic P, Seshiah PN, Dechert MA, Gerthoffer WT, Griendling KK: Phosphoinositide-dependent kinase I and p2I-activated protein kinase mediate reactive oxygen species-dependent regulation of platelet-derived growth factor-induced smooth muscle cell migration. Circ Res 2004 94: $1219-1226$

30. Knaus UG, Wang Y, Reilly AM, Warnock D, Jackson JH: Structura requirements for PAK activation by Rac GTPases. J Biol Chem 1998, 273:21512-21518.

31. Vadlamudi RK, Bagheri-Yarmand R, Yang Z, Balasenthil S, Nguyen D, Sahin AA, den Hollander P, Kumar R: Dynein light chain I, a p2 Iactivated kinase I-interacting substrate, promotes cancerous phenotypes. Cancer Cell 2004, 5:575-585.

32. Vadlamudi RK, Li F, Adam L, Nguyen D, Ohta Y, Stossel TP, Kumar $\mathrm{R}$ : Filamin is essential in actin cytoskeletal assembly mediated by p2I-activated kinase I. Nat Cell Biol 2002, 4:68I-690.

33. Bokoch GM, Wang Y, Bohl BP, Sells MA, Quilliam LA, Knaus UG: Interaction of the Nck adapter protein with p2l-activated kinase (PAKI). J Biol Chem 1996, 27 I:25746-25749.

34. Vadlamudi RK, Barnes CJ, Rayala S, Li F, Balasenthil S, Marcus S, Goodson HV, Sahin AA, Kumar R: p2 I-activated kinase I regulates microtubule dynamics by phosphorylating tubulin cofactor B. Mol Cell Biol 2005, 25:3726-3736.

35. Singh RR, Song C, Yang Z, Kumar R: Nuclear localization and chromatin targets of p2 I-activated kinase I. J Biol Chem 2005 , 280:18130-18137.

36. Dharmawardhane S, Schurmann A, Sells MA, Chernoff J, Schmid SL Bokoch GM: Regulation of macropinocytosis by $\mathrm{p} 2 \mathrm{I}$-activated kinase-I. Mol Biol Cell 2000, I I:334I-3352.

37. Hamasaki M, Araki N, Hatae T: Association of early endosoma autoantigen I with macropinocytosis in EGF-stimulated A43 I cells. Anat Rec A Discov Mol Cell Evol Biol 2004, 277:298-306.

38. Swanson JA, Watts C: Macropinocytosis. Trends Cell Biol 1995 5:424-428.

39. Bar-Sagi D, Feramisco JR: Induction of membrane ruffling and fluid-phase pinocytosis in quiescent fibroblasts by ras proteins. Science 1986, 233:106I-1068.

40. Dowrick P, Kenworthy P, McCann B, Warn R: Circular ruffle formation and closure lead to macropinocytosis in hepatocyte growth factor/scatter factor-treated cells. Eur J Cell Biol 1993, 6I:44-53.

4I. Buccione R, Orth JD, McNiven MA: Foot and mouth: podosomes, invadopodia and circular dorsal ruffles. Nat Rev Mol Cell Biol 2004, 5:647-657.

42. Ridley AJ: Pulling back to move forward. Cell 2004, I I 6:357-358.

43. Wilusz C], Wormington M, Peltz SW: The cap-to-tail guide to mRNA turnover. Nat Rev Mol Cell Biol 200I, 2:237-246.

44. Cora D, Herrmann C, Dieterich C, Di Cunto F, Provero P, Caselle M: $A b$ initio identification of putative human transcription factor binding sites by comparative genomics. BMC Bioinformatics 2005, 6: I 10 .

45. Keene JD: RNA regulons: coordination of post-transcriptional events. Nat Rev Genet 2007, 8:533-543.

46. Bryant DM, Stow JL: The ins and outs of E-cadherin trafficking. Trends Cell Biol 2004, 14:427-434.

47. Frank DJ, Noguchi T, Miller KG: Myosin VI: a structural role in actin organization important for protein and organelle localization and trafficking. Curr Opin Cell Biol 2004, I 6: I89-194.

48. Souchelnytskyi S: Bridging proteomics and systems biology: what are the roads to be traveled? Proteomics 2005, 5:4I23-4I37.

49. De Matteis MA, Morrow JS: Spectrin tethers and mesh in the biosynthetic pathway. J Cell Sci 2000, I I 3:233 I-2343.

50. Holleran EA, Tokito MK, Karki S, Holzbaur EL: Centractin (ARPI) associates with spectrin revealing a potential mechanism to link dynactin to intracellular organelles. J Cell Biol 1996, I35:1815-1829.

5I. Banerjee M, Worth D, Prowse DM, Nikolic M: Pak I phosphoryla- tion on t2 12 affects microtubules in cells undergoing mitosis. Curr Biol 2002, I 2: I 233-1239.

52. UniGene ID Extraction Tool [http://kdd.di.unito.it/biology/uni gene.php]

53. Kyoto Encyclopedia of Genes and Genomes [http:// www.genome.jp/kegg/pathway.html]

54. National Center for Biotechnology Information [http:// www.ncbi.nlm.nih.gov/]

55. Geiger B, Bershadsky A, Pankov R, Yamada KM: Transmembrane crosstalk between the extracellular matrix - cytoskeleton crosstalk. Nat Rev Mol Cell Biol 200I, 2:793-805.

56. Andersen JS, Wilkinson C], Mayor T, Mortensen P, Nigg EA, Mann M Proteomic characterization of the human centrosome by protein correlation profiling. Nature 2003, 426:570-574.

57. Schroer TA: Dynactin. Annu Rev Cell Dev Biol 2004, 20:759-779.

58. Vartiainen MK, Machesky LM: The WASP-Arp2/3 pathway: genetic insights. Curr Opin Cell Biol 2004, I 6: I74-|8|

59. Raijmakers R, Schilders G, Pruijn G]: The exosome, a molecular machine for controlled RNA degradation in both nucleus and cytoplasm. Eur I Cell Biol 2004, 83: I 75-I83.

60. Lipschutz $\mathrm{JH}$, Mostov KE: Exocytosis: the many masters of the exocyst. Curr Biol 2002, I 2:R2 I2-2| 4.

6I. Amit S, Hatzubai A, Birman Y, Andersen JS, Ben-Shushan E, Mann M, Ben-Neriah Y, Alkalay I: Axin-mediated CKI phosphorylation of beta-catenin at Ser 45: a molecular switch for the Wnt pathway. Genes Dev 2002, I 6:1066-1076.

62. Simone C: SWI/SNF: the crossroads where extracellular signaling pathways meet chromatin. J Cell Physiol 2006, 207:309-3|4.

63. Lenka N, Vijayasarathy C, Mullick J, Avadhani NG: Structural organization and transcription regulation of nuclear genes encoding the mammalian cytochrome c oxidase complex. Prog Nucleic Acid Res Mol Biol 1998, 6 I:309-344.

64. Cai J, Gibbs E, Uhlmann F, Phillips B, Yao N, O'Donnell M, Hurwitz ]: A complex consisting of human replication factor $C$ p40, p37, and p36 subunits is a DNA-dependent ATPase and an intermediate in the assembly of the holoenzyme. J Biol Chem 1997, 272: |8974-|898|.

65. Vasile E, Oka T, Ericsson M, Nakamura N, Krieger M: IntraGolgi distribution of the conserved oligomeric Golgi (COG) complex. Exp Cell Res 2006, 3 I 2:3|32-3|41.

66. Mogridge J: Using light scattering to determine the stoichiometry of protein complexes. Methods Mol Biol 2004, 26 I: I I3-I I 8.

67. Neet KE, Lee JC: Biophysical characterization of proteins in the post-genomic era of proteomics. Mol Cell Proteomics 2002, I:415-420.

68. Zou M, Conzen SD: A new dynamic Bayesian network (DBN) approach for identifying gene regulatory networks from time course microarray data. Bioinformatics 2005, 21:71-79.

69. Cascone I, Audero E, Giraudo E, Napione L, Maniero F, Philips MR, Collard JG, Serini G, Bussolino F: Tie-2-dependent activation of RhoA and Racl participates in endothelial cell motility triggered by angiopoietin-I. Blood 2003, 102:2482-2490.

70. Scott JK, Smith GP: Searching for peptide ligands with an epitope library. Science 1990, 249:386-390.

7I. Smith GP, Scott JK: Libraries of peptides and proteins displayed on filamentous phage. Methods Enzymol 1993, 2 I 7:228-257. 